\title{
Excesso de Velocidade no Trânsito: Análise Sob a Perspectiva da Moralidade
}

Speeding: Analysis Under Morality Perspective

Exceso de Velocidad en el Tránsito: Análisis Bajo la Perspectiva de la Moralidad

Gislei Mocelin Polli, lara Picchioni Thielen, Ricardo Carlos Hartmann \& Diogo Picchioni Soares

Universidade Federal do Paraná

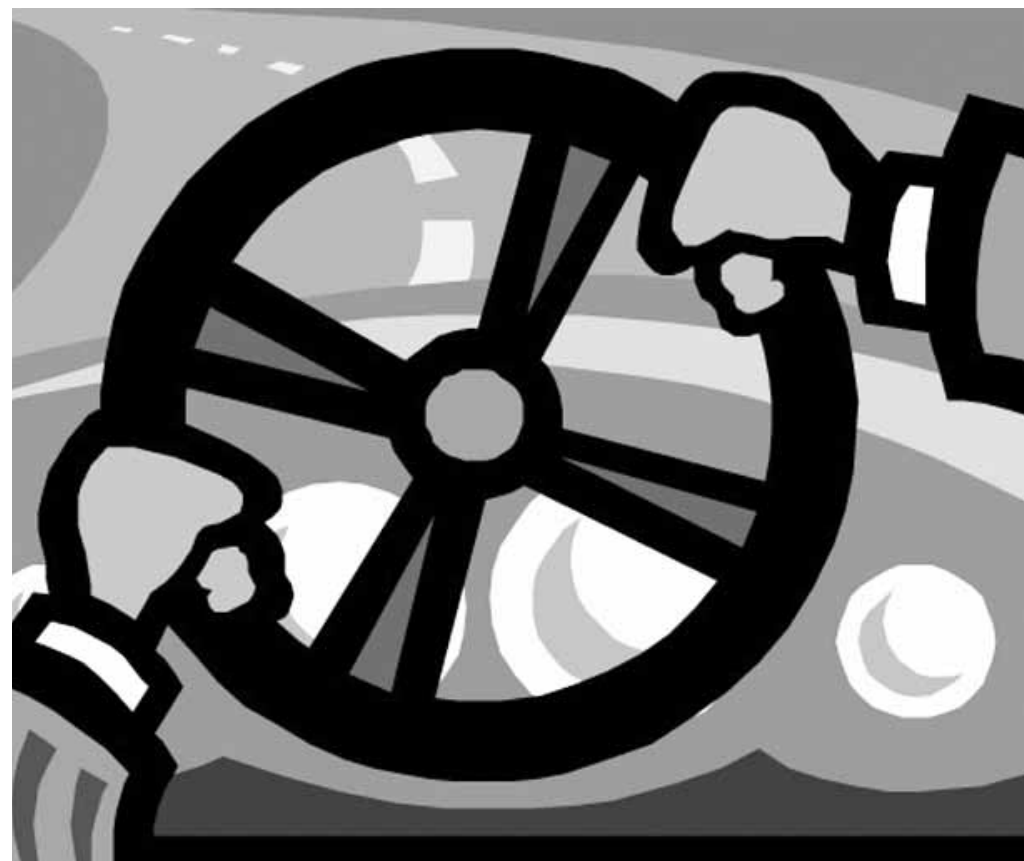


Resumo: Este trabalho focaliza o desenvolvimento moral como um dos fatores relacionados ao comportamento inadequado no trânsito. O objetivo foi estudar a relação entre o nível de desenvolvimento moral e o comportamento infrator dos motoristas, partindo da hipótese que a infração estaria relacionada com os primeiros estágios de desenvolvimento moral propostos por Kohlberg. Para esta pesquisa, foram analisadas entrevistas qualitativas com 20 motoristas com mais de nove multas por excesso de velocidade, das quais 49 respostas foram selecionadas, já que as demais não possibilitavam análise do nível de desenvolvimento moral. O estudo permitiu verificar que o estágio 1 de desenvolvimento moral predomina em 75,51\% das respostas dos motoristas infratores entrevistados. A característica principal desse estágio é a preocupação com a punição, expressa na resposta "eu não sabia que ali tinha radar". Essa resposta indica que, se não houvesse fiscalização e, em consequência, punição, não haveria motivo para não infringir a lei. Este estudo indica limitações na aplicação da teoria de desenvolvimento moral baseada nas justificativas, pois estas se aplicam a ações infratoras ou não. Além disso, o estudo não focalizou dilemas e privilegiou a análise das respostas, portanto, o estágio 1 foi característico de respostas, e não de sujeitos.

Palavras-chave: Acidentes de trânsito. Assunção de riscos. Veículos automotores. Desenvolvimento moral.

\begin{abstract}
This research focuses on moral development as one of the factors related to the inadequate behavior in traffic. It aims at verifying the relation between the moral development level and the driver's law-breaking behavior, starting from the hypothesis that the infraction is related to the primary stages of moral development proposed by Kohlberg. The interviews with 20 drivers, each one with more than 9 fines, were qualitatively analyzed, from which 49 answers were selected for the analysis of the moral development stages. The remaining answers could not be used with that purpose. The analysis led to the conclusion that the level 1 of moral development prevails in $75.51 \%$ of the answers. The main characteristic in this stage is the concern with punishment, when the drivers said: "I didn't know that there was a radar there". This answer signs that enforcement and consequently punishment justify the non-infractor behavior. This study shows limitations on the use of the moral development theory based on justifications, since they apply to infractor or non-infractor action. This paper didn't focus on dilemmas, but the analysis focused on answers, not on subjects. So, the first stage was characteristic of answers, not of subjects.
\end{abstract}

Keywords: Traffic accidents. Risk-taking. Motor vehicles. Moral development.

Resumen: Este trabajo enfoca el desarrollo moral como uno de los factores relacionados al comportamiento inadecuado en el tránsito. El objetivo fue estudiar la relación entre el nivel de desarrollo moral y el comportamiento infractor de los conductores, partiendo de la hipótesis de que la infracción estaría relacionada con los primeros estados de desarrollo moral propuestos por Kohlberg. Para esta pesquisa, fueron analizadas entrevistas cualitativas con 20 conductores con más de nueve multas por exceso de velocidad, de las cuales 49 respuestas fueron seleccionadas, ya que las demás no posibilitaban análisis del nivel de desarrollo moral. El estudio permitió verificar que el estado 1 de desarrollo moral predomina en un $75,51 \%$ de las respuestas de los conductores infractores entrevistados. La característica principal de ese estado es la preocupación con el castigo, expresada en la respuesta "yo no sabía que allí había radar". Esa respuesta indica que, si no hubiese fiscalización y, en consecuencia, castigo, no habría motivo para no infringir la ley. Este estudio indica limitaciones en la aplicación de la teoría de desarrollo moral basada en las justificativas, pues éstas se aplican a acciones infractoras o no. Además, el estudio no enfocó dilemas y privilegió el análisis de las respuestas, por tanto, el estado 1 fue característico de respuestas, y no de sujetos. Palabras clave: Accidentes de tránsito. Asunción de riesgos. Vehículos automotores. Dessarollo moral.

O trânsito caracteriza-se por um conjunto de deslocamentos de pessoas e de veículos nas vias públicas, regulados por normas, que visam a garantir a integridade de seus participantes (Rozestraten, 1988). O trânsito no Brasil é um dos piores e mais perigosos do mundo, causando muitas mortes e deficiências físicas, além de gastos hospitalares com vítimas de acidentes (Marín \& Queiroz, 2000). O relatório apresentado pelo Instituto de Pesquisa Econômica Aplicada (IPEA, 2003) referente às aglomerações urbanas indica que a taxa de mortos/10.000 veículos no Brasil, em 2000, era de 6,80, enquanto no Japão era de 1,32, na Alemanha, de 1,46, nos Estados Unidos, de 1,93, e, na Turquia, de 5,36. O Relatório Estatístico referente a 2007 indica que ocorreram 151.186 acidentes com vítimas no Brasil, sendo 6.885 fatais (Departamento Nacional de Trânsito [DENATRAN], 2008). Levando em consideração que o Departamento Nacional 
de Trânsito (DENATRAN) determina o registro de mortes apenas no local, a dimensão da violência é mais ampla que a indicada pelo Registro Nacional de Acidentes e Estatísticas de Trânsito (RENAEST) do DENATRAN. O relatório do Instituto de Pesquisa Econômica Aplicada/Departamento Nacional de Trânsito (IPEA/DENATRAN, 2006), referente aos acidentes em rodovias, indica um acréscimo de $66 \%$ aproximadamente, pois no segundo semestre de 2004 foram registradas 6.119 mortes no local e 4.067 mortes pós-acidente.

Marín e Queiroz (2000) destacam que 2/3 dos acidentes de trânsito que causam ferimentos ocorrem em áreas urbanas, e indicam que o gasto dos países com nível de desenvolvimento intermediário com medidas resultantes de acidentes de trânsito representa cerca de $1 \%$ do produto nacional bruto. Os dados do IPEA indicam um custo de $1,2 \%$ do PIB brasileiro (IPEA/DENATRAN, 2006).

Diversas medidas têm sido propostas no Brasil com o objetivo de reduzir o elevado número de mortos e feridos decorrentes da violência no trânsito: a promulgação do Código de Trânsito Brasileiro, em 1997 (Brasil, 1997); a formalização da Política Nacional de Redução da Morbimortalidade por Acidentes e Violências, pelo Ministério da Saúde, em 2001; e a promulgação da Lei no 11.705/08, em 2008, que estabeleceu a alcoolemia zero e impôs penalidades mais severas ao condutor que dirige sob influência do álcool, mostrando-se capaz de reduzir os atendimentos nas emergências dos hospitais em cerca de $24 \%$, conforme divulgado pelo Ministério da Saúde: a maior queda em resgates foi registrada na região de Niterói (RJ), que corresponde a 47\%; em Brasília, houve uma redução de $40 \%$, em Porto Alegre (RS), a queda foi de 35\% (Ministério da Saúde, 2008).
Rozestraten (1988) indica que o fator humano está relacionado a $85 \%$ dos acidentes e enumera três categorias de fatores humanos acidentogênicos: 1) ligados a processos básicos (tomada de informação, processamento da informação, tomada de decisão, reação, feedback); 2) ligados à personalidade (propensão ao acidente, desajuste social, desajuste pessoal, estilo perceptivo, uso do veículo para fins secundários); e 3) fatores passageiros (fadiga, drogas, álcool).

O comportamento do motorista é o principal fator responsável pelos acidentes de trânsito no que se refere à observação de sinais, velocidade e decisões no momento de ultrapassar outro carro ou de cruzar uma via. Marín e Queiroz (2000) indicam a necessidade de maior conhecimento sobre culturas e condições de vida locais para a compreensão das atitudes dos motoristas, a fim de desenvolver programas de capacitação, reabilitação e educação.

Com o objetivo de compreender o comportamento humano no trânsito, Thielen (2002) analisou o comportamento de exceder a velocidade em dois grupos de motoristas: com e sem multas. Embora a pesquisa (Thielen, Hartmann \& Soares, 2008) não focalizasse a questão da moralidade, a análise de algumas das respostas dos motoristas indicava componentes que poderiam ser esclarecidos a partir da teoria de Kohlberg (1981) sobre o desenvolvimento moral. Um dos fatores que interferem no comportamento dos motoristas pode estar pautado no nível de desenvolvimento moral do indivíduo, e seu estudo pode auxiliar na busca de uma explicação para o comportamento na situação de trânsito.

O nível de desenvolvimento moral de um indivíduo exerce influência sobre o julgamento emitido frente a diversas situações. Diferentes fatores são considerados, e, para cada estágio de desenvolvimento moral, existe uma forma 
Os estudos de Piaget (1932) sobre desenvolvimento moral foram aprofundados por Lawrence Kohlberg,

que, de acordo com Freitag (1997, p. 192), "confirmou e consolidou a tese do paralelismo entre lógica e moral, a teoria dos estágios e a universalidade dos processos cognitivos e morais...". de julgar determinada ação ou de escolher determinada forma de agir em um contexto específico. Ao analisar o julgamento de um sujeito frente a determinadas situações, é possível encontrar indicativos sobre o estágio de desenvolvimento moral que alcançou (ou a partir do qual opera). A utilização do referencial da moralidade, a partir de Kohlberg, pode elucidar a construção das justificativas apresentadas pelos motoristas infratores para o excesso de velocidade estudado, permitindo ampliar o espectro de análise do comportamento humano no trânsito.

Este estudo toma como ponto de partida a ação infratora, uma vez que foram analisadas respostas dos sujeitos frente à situação real ocorrida, diferentemente da proposta de Kohlberg, que utilizou dilemas hipotéticos tanto para investigar o desenvolvimento moral quanto para propor, a partir deles, formas de intervenção visando a propiciar uma elevação dos níveis de moralidade. Essas diferenças na base dos estudos devem ser incorporadas na análise dos resultados, indicando os limites e as possibilidades das interpretações.

\section{A teoria dos estágios de desenvolvimento moral de Kohlberg}

A moralidade é uma preocupação presente desde os filósofos gregos, passando pelos filósofos modernos e chegando à Sociologia (Araújo, 1999; Freitag, 1997). Nesse campo, a Psicologia tem uma contribuição importante, já que a moralidade foi cuidadosamente estudada por dois autores: Piaget e Kohlberg. O presente estudo se baseou na teoria de Kohlberg.

Os estudos de Piaget (1932) sobre desenvolvimento moral foram aprofundados por Lawrence Kohlberg, que, de acordo com Freitag (1997, p. 192), "confirmou e consolidou a tese do paralelismo entre lógica e moral, a teoria dos estágios e a universalidade dos processos cognitivos e morais...". A teoria desenvolvida por Kohlberg (1981) postula a crença na universalidade dos valores morais. Para Kohlberg, os princípios éticos são diferentes de regras e crenças desenvolvidas culturalmente, e a sequência de estágios, além de universal, é hierárquica e invariante, embora nem todos atinjam os estágios mais elevados (Biaggio, Vargas, Monteiro, Souza, \& Tesche, 1999). Kohlberg admitia que os indivíduos poderiam manifestar raciocínios de estágios adjacentes, mas não utilizariam ou teriam acesso a raciocínios de dois ou mais estágios acima de seu estágio dominante (Bernardes \& Kohler, 1997; Kohlberg, 1971).

Kohlberg define três níveis de desenvolvimento moral - pré-convencional, convencional e pós-convencional - subdivididos em dois estágios cada um (Kohlberg, 1971, 1981). Segundo o autor, no nível pré-convencional, o julgamento moral tem como referência o próprio indivíduo. Nesse nível, o indivíduo ainda não internalizou os princípios morais; a consequência adquire maior importância, configurando motivação para o ato. No estágio 1, o objetivo é evitar a punição, e, no estágio 2, o objetivo é a satisfação pessoal.

No nível convencional, o julgamento moral considera algumas regras externas: aprovação social, no estágio 3, e a lei, no estágio 4. O nível convencional é caracterizado pela internalização de regras, e os atos são motivados pela busca da aceitação dos companheiros, pelo respeito à ordem estabelecida e pelo bem-estar do grupo.

No nível pós-convencional, os parâmetros se situam além das normas sociais, pois o indivíduo é capaz de perceber inadequações na lei e vai procurar modificá-la, o que caracteriza o estágio 5, ou os princípios universais serão os balizadores das decisões, 
configurando o estágio 6. O nível pósconvencional pode ser atingido por qualquer indivíduo; no entanto, apenas $5 \%$ dos adultos chegam a atingi-lo, geralmente após 20 a 25 anos de idade (Biaggio, 1997; Biaggio et al., 1999; Loos, Ferreira, \& Vasconcelos, 1999). Tal nível ocorre quando o indivíduo se torna capaz de perceber que algumas leis são moralmente erradas e busca modificá-las, transcendendo, assim, o nível que muitos autores definem como ponto terminal do desenvolvimento moral, que é a internalização das normas e valores da sociedade (Biaggio, 1997).

O raciocínio moral se expressa nas justificativas verbais dadas pelos indivíduos em resposta a dilemas. Os dilemas de Kohlberg exigem escolhas extremadas entre ações opostas sobre questões de vida \& morte, autoridade \& contrato, consciência \& punição, nas quais o indivíduo deve decidir entre a transgressão ou a não transgressão de normas. O sistema de codificação de Kohlberg leva em conta verbalizações relativas aos estágios e considera a média para determinar o nível de raciocínio moral que o indivíduo utiliza com alguma consistência. Os estágios definidos por Kohlberg refletem maneiras de raciocinar, e não conteúdos morais; assim, uma pessoa pode ser classificada em qualquer estágio independentemente da resposta ao dilema, e o que determina a classificação é a argumentação dada à resposta (Bernardes \& Kohler, 1997; Biaggio, 1997).

Kohlberg (1981) ressalta a universalidade do julgamento moral sem privilegiar as diferenças individuais, pois considera que os estágios de desenvolvimento moral não refletem apenas o aprendizado de regras ou valores, mas algo que poderia ocorrer em qualquer cultura. Fundamentada em Kohlberg, Dias (1999, p. 461) enfatiza que "o desenvolvimento moral obedece a uma seqüência progressiva e invariante de estágios, cujo fator promocional de mudança, de um estágio inferior a outro qualitativamente superior, é o conflito cognitivo".

Com base na teoria de desenvolvimento moral de Kohlberg, foi proposta esta investigação, buscando analisar a pertinência da utilização dessa teoria para compreender o comportamento humano no trânsito. Assim sendo, o objetivo deste estudo foi verificar se as características dos estágios de desenvolvimento moral estão presentes nas justificativas apresentadas pelos motoristas ao seu comportamento de infringir a velocidade.

\section{Participantes}

Foram entrevistados 20 motoristas de Curitiba, Paraná, Brasil, multados mais de nove vezes por excesso de velocidade. Essa amostra partiu de uma listagem de 441 motoristas com mais de 9 multas, fornecida pelo DETRAN/ PR. Foram eliminados da pesquisa 421 motoristas pelos seguintes motivos: a) não foi possível localizar 217 por falta de indicação do número de telefone; b) não foi possível nenhum contato com 80 deles, após diversas tentativas em diferentes dias e horários; c) o número de telefone de 54 deles estava incorreto ou desligado; d) após tentativa de contato, 14 deles não deram retorno para os recados; e) 10 motoristas haviam participado do processo de reciclagem; f) 1 motorista se recusou a participar da pesquisa; g) 30 se declararam não autores das infrações; h) 15 deles se declararam autores das infrações, mas não foi possível entrevistá-los.

A amostra aqui analisada foi composta por três mulheres e 17 homens, todos com idade acima de 30 anos; 11 têm curso superior, oito têm o ensino médio e um completou o ensino fundamental; 16 deles costumam dirigir sozinhos, 2 acompanhados (cliente e família) e 2 informaram que $50 \%$ do tempo estão sozinhos. Embora a idade mínima constatada tenha sido de 30 anos, não se pode afirmar que apenas motoristas acima dessa 
faixa etária cometam excesso de velocidade, mas que é essa a idade característica dessa amostra. Além disso, nenhuma análise focalizou qualquer diferença entre homens e mulheres, tendo em vista o número reduzido de participantes.

\section{Instrumento}

O instrumento utilizado por Thielen continha 25 questões, e foi proposto para investigar a percepção de motoristas sobre excesso de velocidade. Algumas respostas apresentaram indicadores de níveis de desenvolvimento moral e foram selecionadas e analisadas neste estudo.

Foram utilizadas nesta pesquisa apenas quatro das 25 questões do instrumento original (Thielen, 2002), a seguir especificadas: 1) o que é excesso de velocidade?; 2) qual o significado de ter mais de 9 multas por excesso de velocidade?; 3) houve mudanças de seu comportamento? Quais?; 4) que fatores contribuíram para que o excesso de velocidade ocorresse? Apenas as respostas a essas quatro questões apresentavam indicadores que permitiam sua análise a partir da teoria de Kohlberg.

É importante destacar que as respostas a todas as 25 questões originais (Thielen, 2002) passaram por um processo de triagem, focalizando a possibilidade de análise a partir do referencial da moralidade. As demais questões excluídas (tais como: qual a distância percorrida por um carro até parar a $80 \mathrm{~km} / \mathrm{h}$, a $60 \mathrm{~km} / \mathrm{h}$, a $40 \mathrm{~km} / \mathrm{h}$; o que seria mais eficaz para reduzir sua velocidade?; em vias onde não há fiscalização eletrônica, existe preocupação com a velocidade?; antes e depois das multas? mudou?) apresentavam respostas sem conteúdos que permitissem a visualização dos cinco níveis propostos por Kohlberg. Algumas delas faziam referência ao conhecimento de processos de frenagem, por exemplo, e, mesmo na seleção feita, nem todos os motoristas apresentaram respostas que permitissem a análise; portanto, o foco se deu a partir de respostas, e não de motoristas.

\section{Análise das respostas}

Para analisar as respostas dos motoristas às quatro questões, foi definido um gabarito correspondente a comportamentos no trânsito, baseado nas características dos estágios de desenvolvimento moral. Para cada estágio, foram definidos os tipos de respostas que seriam ali classificáveis, conforme visualizado na tabela 1. Assim, foram respeitadas as características de cada um dos seis estágios propostos por Kohlberg, buscando delinear justificativas para comportamentos no trânsito que correspondessem a cada um dos estágios. No nível pré-convencional, a centralidade das justificativas no individualismo aparece, seja para evitar a punição, seja para resultar em prazer. Para a análise de justificativas relativas ao trânsito, foram focalizadas as mesmas características.

Embora haja controvérsias sobre a possibilidade de encontrar justificativas do estágio 6 para infrações, mesmo assim foram buscados, nos fundamentos de cada estágio, os elementos que comporiam justificativas aplicáceis à situação de trânsito. No estágio 6, por exemplo, a caracterização das justificativas se centraliza em valores, tal como se definiu no gabarito, destacando a importância de salvar vidas como um valor acima de qualquer regra.

É importante destacar que a etapa inicial foi a elaboração do gabarito, com alguns exemplos extraídos de respostas de motoristas e construídos pela equipe de pesquisa. Após a análise das respostas dos participantes, algumas delas foram incorporadas ao gabarito por serem muito mais elucidativas e por conterem os elementos característicos dos estágios, embora, para alguns deles (2 e 5), não tenha sido encontrada nenhuma resposta, ficando mantido o exemplo proposto pela equipe. 
Tabela 1. Gabarito de respostas para comportamentos no trânsito de acordo com a teoria de Kohlberg.

NÍVEL PRÉ-CONVENCIONAL

Estágio 1 - Orientação para a punição e a obediência. Foram enquadrados neste estágio respostas que faziam referência à fiscalização (radar), ou outra forma de punição, como agente controlador do comportamento. Exemplo: "eu não sabia que ali tinha radar".

Estágio 2 - Hedonismo instrumental relativista. Neste estágio, seriam enquadradas respostas que justificassem o excesso de velocidade pelo prazer ou bem-estar para o próprio motorista. Exemplo: "ando acima da velocidade permitida para chegar logo em casa".

\section{NÍVEL CONVENCIONAL}

Estágio 3 - Moralidade do bom garoto. Neste estágio, o tipo de resposta faz referência à aprovação social. O motorista se refere ao que os outros pensam sobre cometer infrações ou receber multas. Exemplo: "se ando muito devagar os outros grudam atrás e buzinam, sou obrigado a andar mais rápido pela pressão atrás".

Estágio 4 - Orientação para a lei e a ordem. Neste estágio foi incluído todo tipo de respostas que faziam referência à lei como orientadora do comportamento, independentemente da presença de radares ou de qualquer tipo de fiscalização. Exemplo: "se marcar 60 e estiver a 65 já é excesso".

\section{NIVEL PÓS-CONVENCIONAL}

Estágio 5 - Orientação para o contrato social democrático. Neste estágio, seriam enquadradas respostas que questionam se a lei está correta e visa ao bem estar de todos, ou respostas que não utilizam possíveis erros legais como justificativa para seu comportamento infrator. Exemplo: "procuro dirigir de modo a não atrapalhar o bom andamento do trânsito".

Estágio 6 - Princípios universais de consciência. Foram consideradas respostas que, mesmo contrárias à lei em vigor, demonstram preocupações com o bem-estar geral, com o bom andamento do trânsito e com a segurança própria e alheia. Exemplo: "excesso de velocidade se justifica quando há uma pessoa doente no carro que precisa chegar rapidamente ao hospital; a vida é mais importante que as regras do trânsito".

\section{Resultados}

A identificação do nível de moralidade das respostas foi uma tarefa complexa, já que não foi possível definir um padrão para cada motorista. A classificação se deu por resposta analisada, e não por sujeito entrevistado. Uma vez que muitas das respostas não permitiam qualquer classificação, alguns motoristas tiveram apenas uma de suas respostas classificadas, outros apresentaram características de estágios distintos para cada resposta e poucos apresentaram um padrão consistente.

Foram analisadas 80 respostas, das quais 49 forneciam indícios sobre o estágio em que o motorista se encontra (as demais foram excluídas, pois não permitiam análise do nível de desenvolvimento moral): 37 respostas são características do estágio 1 (75,51\%); 8 respostas são características do estágio 4 (16,32\%); 2 respostas são características da transição entre os estágios 4 e 5 (4,08\%); 1 resposta é característica do estágio $3(2,04 \%)$; 1 resposta talvez possa ser caracterizada como do nível pós-convencional, estágio 6 (2,04\%), e os estágios 2 e 5 não aparecem em nenhuma das respostas. 
Foi constatado que, nessa amostra, composta por 20 motoristas com mais de nove multas por excesso de velocidade, as características predominantes nas respostas selecionadas, de acordo com a teoria de Kohlberg, são do estágio 1.

As principais respostas que permitem a classificação no estágio 1 de desenvolvimento moral referem-se à presença de radar como agente regulador do comportamento. Ao analisar a questão: Você tem mais de nove multas por excesso de velocidade. Qual o significado para você?, algumas respostas encontradas foram: "Um desastre. Falta de atenção. Não notei que tinha radar." "Prejuízo. Raiva de pagar tudo isso para o governo, é bem na hora que a gente se distrai. Também, eles colocam os radares em lugares estratégicos. Significa falta de atenção." "Ainda não estou habituado aos radares".

Recorrendo à teoria de Kohlberg (1981), o estágio 1 de desenvolvimento moral é caracterizado pela preocupação com a punição que pode resultar de um determinado comportamento. O comportamento é considerado inadequado se traz resultados danosos a quem o emite. Essa preocupação foi identificada, pois os motoristas respondem tendo como convicção que exceder a velocidade limite determinada pelos órgãos competentes é prejudicial na medida em que esse comportamento é flagrado e gera uma punição, a multa. Fica implícito em muitas respostas que, se não houvesse fiscalização, não haveria motivação para que a lei fosse cumprida. Não é o comportamento de exceder a velocidade que é objeto de análise pelos motoristas, mas a presença do mecanismo de fiscalização eletrônica e, em consequência, a punição, representada pela multa.

O estágio 1 integra o nível pré-convencional. Esse nível pode ser comparado à primeira fase de desenvolvimento moral estudada por Piaget (1932), caracterizada pela falta de interação. A criança brinca sozinha entre outras crianças e, embora esteja no mesmo local, não se relaciona com as demais. Assim também é o motorista que está no primeiro estágio de desenvolvimento moral: dirige entre outros carros, mas não mantém relação com eles, não está preocupado em seguir normas que promovam boas relações para todos, não está preocupado com a coletividade. O referencial para o julgamento moral das ações é seu próprio bem-estar: evitar a punição (multa). O motorista no estágio 1 não analisa o trânsito como um fenômeno coletivo e, portanto, seu julgamento não inclui a repercussão das ações sobre os outros integrantes do sistema. O motorista não percebe que a lei serve para organizar o trânsito, possibilitando que cada um, ao cumprir seu papel, facilite também ao outro realizar seu trajeto com segurança, o que corresponderia a um julgamento moral característico do nível 2, convencional.

São características do nível convencional: a preocupação com as relações sociais, com o bom andamento do trânsito, e a compreensão de que o trânsito é coletivo e que, portanto, os outros (motoristas, pedestres, ciclistas e motociclistas) que transitam no espaço público devem ser considerados nas ações individuais. É o nível em que o indivíduo está além das preocupações egocêntricas, incluindo o contexto social em seu julgamento e no qual predomina o parâmetro social das ações: no estágio 3, a preocupação é com a aprovação social, e, no estágio 4, o parâmetro legal é o norteador. No trânsito, as ações estão regulamentadas pelo Código de Trânsito Brasileiro (Brasil, 1997), que estabelece as determinações que promovem a segurança para os integrantes, estabelecendo regras aplicáveis a todos, e seu descumprimento sempre provoca danos. 
O estágio 3 é caracterizado pela busca de aprovação social, pela intenção de agir corretamente de acordo com o julgamento alheio. A seguinte resposta de um dos motoristas caracteriza a motivação social para o comportamento: "Eu tinha um hábito errado. Tinha excesso de velocidade. Se as pessoas andam muito devagar, outros grudam e buzinam. É obrigado a andar mais rápido pela pressão atrás", ou seja, a justificativa para o comportamento se baseia na pressão externa, do grupo, em que a pessoa busca atender a aprovação social e procura se comportar a partir daquilo que é esperado pelos outros.

O estágio 4, que integra o nível convencional, foi o mais encontrado nas respostas dos motoristas infratores, após o estágio 1 . O estágio 4 é caracterizado pela obediência às normas. Ao analisar as respostas à questão: O que é excesso de velocidade?, é possível identificar o quarto estágio de desenvolvimento moral expresso nas palavras: "Além do que é estabelecido. Tem via que é 60 - se está a mais, é excesso". "Se marcar 60 e estiver a 65, já é excesso". Nesse nível, o papel da lei e da ordem é fundamental.

O nível pós-convencional se caracteriza pela preocupação com o bem-estar geral, e o parâmetro de julgamento das ações está baseado em princípios universais. No estágio 5, essa preocupação se manifesta no engajamento em mudanças na legislação que possam atender os princípios universais. No estágio 6, o julgamento moral pode se confrontar com a lei, quando esta fere os princípios universais, ou seja, se determinada lei fere princípios universais, o indivíduo age de acordo com os princípios, e não de acordo com a lei. Ao responder à pergunta "O que é excesso de velocidade?", um dos motoristas extrapolou as determinações legais e sociais e incluiu um julgamento mais geral ao afirmar: "a partir de determinado limite, em qualquer circunstância se considera excesso. Dependendo das condições de equilíbrio, sanidade e perícia, $30 \mathrm{~km}$ deve ser considerado excesso de velocidade. Em parte, é determinado pelas condições da pessoa e do local, em outra parte, a própria velocidade (acima de 100,120). Andar na cidade a 100, 120, como pode? Deve-se compatibilizar velocidade com vias de escoamento rápido. No aterro do Flamengo, se for 60, para tudo".

A resposta parece indicar uma preocupação global, não com a possibilidade de multa ou de prazer (características do nível préconvencional) nem com a necessidade de atender ao que se espera de um bom motorista ou de cumprir cegamente a lei (características do nível convencional), mas uma preocupação em destacar que há interações possíveis entre diversos fatores que alteram as determinações legais para a definição de excesso de velocidade. A resposta indica que caberia ao motorista estar atento a essas interações e descobrir que limite de velocidade possibilita a ausência de problemas nas relações no trânsito, ou seja, essa resposta indica a preocupação com a análise das determinações legais, mas vai além delas, já que propõe sua discussão. Há um questionamento da determinação estanque de uma velocidade que poderia ser considerada excessiva. Talvez seja possível, portanto, caracterizar essa resposta como pertencente ao nível pós-convencional. Ao mesmo tempo, há questionamentos de que essa resposta apenas transfigura a determinação legal, sem que haja qualquer preocupação característica do nível pós-convencional, já que não está explicitada. Esse motorista enfatizou "a pessoa, o local ou a própria velocidade", e não qualquer consequência que afetasse direitos fundamentais.

A análise dessa resposta atesta a dificuldade da aplicação da teoria em situação específica do trânsito, uma vez que múltiplos fatores 
parecem concorrer para as justificativas e demandam outras análises integradas. Mas, de qualquer forma, essa teoria permitiu o estudo do comportamento no trânsito sob a ótica da moralidade, acenando para a relação entre infração e julgamento moral da ação a partir de referenciais autocentrados, focalizando a punição e a obediência.

\section{Considerações finais}

Para investigar a presença de características dos níveis de desenvolvimento moral presentes em afirmativas de motoristas infratores, foram analisados dados obtidos através de entrevistas realizadas com 20 motoristas infratores por excesso de velocidade da região de Curitiba, Paraná. A partir da utilização da teoria de desenvolvimento moral elaborada por Kohlberg $(1971,1981)$, foi possível verificar que o nível pré-convencional predomina na amostra entrevistada, representado pelo estágio 1 - orientação para a punição e a obediência, cujo julgamento moral se pauta pelas consequências diretas da ação, ao autor. A resposta característica desse nível é: "Eu não sabia que ali tinha radar". Dentre as 49 respostas analisadas, foram encontradas 37 como a exemplificada, o que representou $75,51 \%$ do total.

A predominância do estágio 1 nas afirmativas dos motoristas infratores pode indicar que eles não estão preocupados em seguir regras pelo bem da sociedade, ou em buscar o bem-estar de todos nem a adequação às normas sociais, tampouco estão preocupados com o bom andamento do trânsito ou em não arriscar sua própria vida ou a de outros. O seu comportamento é justificado pelas consequências da ação, em termos de punição. Esse tipo de raciocínio moral caracteriza a ação de acordo com as normas apenas onde há risco de punição, ou seja, de fiscalização, que, no caso do excesso de velocidade, se expressa através da presença do radar.
Nas respostas da maioria dos entrevistados, constata-se que não é necessário transitar dentro dos limites impostos em toda a via, mas apenas onde há fiscalização. A motivação para cumprir a lei não é evitar acidentes graves ou atropelamentos, mas não ser flagrado pelo instrumento de fiscalização eletrônica, não sofrer as sanções legais, não pagar multa, portanto, não ser punido: uma justificativa típica do estágio 1 de desenvolvimento moral, conforme Kohlberg.

Se for considerada a redução nos atendimentos das emergências, a partir da lei seca - Lei no 11.705/08, é possível encontrar o parâmetro da punição regendo os comportamentos. Em outras palavras, a partir do momento em que a relação entre a punição severa e o comportamento infrator (dirigir sob influência de álcool) foi demarcada, houve redução significativa das ocorrências atendidas nos hospitais. É possível inferir que a justificativa para essa redução possa estar relacionada com o estágio 1 de moralidade de Kohlberg: para evitar a punição.

Embora tenha sido possível identificar características do primeiro estágio de desenvolvimento moral nessa amostra de motoristas infratores, algumas considerações sobre o uso da teoria de Kohlberg devem ser enfatizadas.

Primeiramente, é importante ressaltar que, para Kohlberg, a justificativa que o sujeito apresenta caracteriza cada estágio de desenvolvimento moral, portanto, não é a ação que está em jogo. Com base na teoria, seria possível identificar o estágio 1 também em motoristas não infratores.

Em segundo lugar, os estudos de Kohlberg sempre tiveram como ponto de partida os dilemas morais que demandavam escolhas e as justificativas dessas escolhas. No presente estudo, o ponto de partida foi uma ação infratora, e não um dilema. Deve-se ressaltar 
que os trabalhos de Kohlberg foram propostos sobre dilemas hipotéticos, e este estudo se baseou em fatos reais ocorridos: sujeitos multados.

Além dessas considerações teóricas, a análise empreendida neste estudo focalizou as respostas, e não os sujeitos, e, assim, não pode inferir os estágios de desenvolvimento moral dos indivíduos, mas apenas características dos estágios nas suas afirmativas. Embora essas considerações finais sejam assinaladas, foi possível encontrar uma vertente de pesquisa que pode indicar interações importantes entre moralidade e trânsito, ainda que outras teorias possam ser também consideradas fundamento em novas perspectivas de análise. A limitação importante da teoria ora utilizada se dá em relação ao significado da ação para a segurança no trânsito.

Considerando-se a centralidade da ação no trânsito, foram observadas características do comportamento humano frente às regras de circulação bem como algumas decorrências quando essas regras não são seguidas. Enfatizamos a importância de incorporar a ação no trânsito nos estudos sobre moralidade, por isso acreditamos que esta pesquisa tanto possa servir de base para outros estudos sobre a relação entre moralidade e comportamentos infratores como para levantar questões importantes a serem investigadas no âmbito da saúde e da segurança no trânsito.

\section{Gislei Mocelin Polli}

Mestre e Doutouranda em Psicóloga, formada pela Universidade Federal do Paraná, Curitiba, PR - Brasil. Integrante do Núcleo de Psicologia do Trânsito Universidade Federal do Paraná como colaboradora, doutoranda em Psicologia pela Universidade Federal de Santa Catarina, Florianópolis, SC - Brasil. E-mail: gismocelin@gmail.com

\section{Iara Picchioni Thielen}

Professora da Universidade Federal do Paraná, Curitiba, PR - Brasil. Doutora em Ciências Humanas Sociedade e Meio Ambiente, pela Universidade Federal de Santa Catarina, Florianópolis, SC - Brasil. Coordenadora do Núcleo de Psicologia do Trânsito da Universidade Federal do Paraná.

E-mail: iara.thielen@gmail.com

\section{Ricardo Carlos Hartmann}

Mestre em Arquitetura e Urbanismo. Psicólogo, Especialista em Cidade, Meio Ambiente e Políticas Públicas pela Universidade Federal do Paraná, Curitiba, PR - Brasil; integrante do Núcleo de Psicologia do Trânsito da Universidade Federal do Paraná como colaborador.

\section{Diogo Picchioni Soares}

Psicólogo, ex-bolsista do Núcleo de Psicologia do Trânsito da Universidade Federal do Paraná, PR - Brasil. Mestrando em Psicologia pela Universidade Federal do Paraná. Bolsista CAPES/REUNI.

\section{Endereço para envio de correspondência:}

Universidade Federal do Paraná - Núcleo de Psicologia do Trânsito - Praça Santos Andrade, 50, sala 105 Curitiba, PR - Brasil - CEP: 80060-240. 


\section{Referências}

Araújo, U. F. (1999). Conto de escola: a vergonha como um regulador moral. São Paulo: Moderna.

Bernardes, N. M. G., \& Koller, S. H. (1997). Desenvolvimento moral pró-social: semelhanças e diferenças entre os modelos teóricos de Eisenberg e Kohlberg. Estudos de Psicologia, 2(2), 223-262. Recuperado em 17 de janeiro de 2007, da SciELO (Scientific Electronic Library Online): http://www. scielo.br/scielo/

Biaggio, A. M. B. (1997). Kohlberg e a comunidade justa: promovendo o senso ético e a cidadania na escola. Psicologia: Reflexão e Crítica, 10(1), 47-69. Recuperado em 17 de janeiro de 2007, da SciELO (Scientific Electronic Library Online): http://www.scielo.br/scielo/

Biaggio, A. M. B., Vargas, G. A. O., Monteiro, J. K., Souza, L. K., \& Tesche, S. L. (1999). Promoção de atitudes ambientais favoráveis através de debates de dilemas ecológicos. Estudos de Psicologia, 4(2), 221-239. Recuperado em 17 de janeiro de 2007, da SciELO (Scientific Electronic Library Online): http://www.scielo.br/scielo/

Brasil. (1977). Lei $n^{\circ}$ 9.503, de 23 de setembro. Código de Trânsito Brasileiro.

Brasil. (2008). Lei $n^{\circ}$ 11.705, de 19 de junho. Altera o Código Brasileiro de Trânsito.

Departamento Nacional de Trânsito. (2008). Portal RENAEST. Recuperado em 20 de julho de 2008, de http://www. denatran.gov.br

Dias, A. A. (1999). Educação moral para a autonomia. Psicologia: Reflexão e Crítica, 10(2), 459-478. Recuperado em 19 de janeiro de 2007, da SciELO (Scientific Electronic Library Online): http://www.scielo.br/scielo/

Freitag, B. (1997). Itinerários de Antígona: a questão da moralidade (2a ed.). Campinas, SP: Papirus.

Instituto de Pesquisa Econômica Aplicada. (2003). Impactos sociais e econômicos dos acidentes de trânsito nas aglomerações urbanas. Síntese da pesquisa. Brasília, DF. Recuperado em 20 julho 2008, de http://www.denatran. gov.br

Instituto de Pesquisa Econômica Aplicada/Departamento Nacional de Trânsito. (2006). Impactos sociais e econômicos dos acidentes de trânsito nas rodovias brasileiras. Relatório executivo. Brasília, DF: Autor. Recuperado em 20 de julho de 2008, de http://www.denatran.gov.br
Kohlberg, L. (1971). From is to ought: How to commit the naturalistic fallacy and get away it in the study of moral development. In T. S. Mischel (Ed.), Cognitive development and epistemology (pp. 101-189, C. de F. Nascimento, Trad.). New York: Academic Press.

Kohlberg, L. (1981) Essays on moral development: Vol. 1. The philosophy of moral development. (C. de F. Nascimento, Trad.). Recuperado em 1 de setembro de 2004 de, http:// www.ccp.uchicago.edu

Loos, H, Ferreira, S. P. A., \& Vasconcelos, F. C. (1999). Julgamento moral: estudo comparativo entre crianças institucionalizadas e crianças de comunidade de baixa renda com relação à emergência do sentimento de culpa. Psicologia: Reflexão e Crítica, 12(1), 47-70. Recuperado em 19 de janeiro de 2007, da SciELO (Scientific Electronic Library Online): http://www. scielo.br/scielo/

Marín, L. A., \& Queiroz, M. S. (2000). Atualidade dos acidentes de trânsito na era da velocidade: uma visão geral. Cadernos de Saúde Pública, 16(1). Recuperado em 19 de janeiro de 2007, da SciELO (Scientific Electronic Library Online): http:// www.scielo.br/scielo/

Ministério da Saúde. (2001). Portaria $n^{\circ}$ 737, de 16 de maio, que dispóe sobre a Política Nacional de Redução da Morbimortalidade por Acidentes e Violências. Brasília, DF. Autor.

Ministério da Saúde. (2008). Lei seca reduz operações de resgate de urgência. Dados de 14/07/2008. Recuperado em 20 de julho de 2008, de http://189.28.128.100/portal/aplicacoes/ noticias/noticias_detalhe.cfm?co_seq_noticias $=51038$

Piaget, J. (1932). El juicio moral en el niño. Madrid: Francisco Beltrán.

Rozestraten, R. J. A. (1988). Psicologia do trânsito: conceito e processos básicos. São Paulo: EPU.

Thielen, I. P. (2002). Percepções de motoristas sobre excesso de velocidade no trânsito de Curitiba, Paraná, Brasil. Tese de Doutorado, Universidade Federal de Santa Catarina. Recuperado em 19 de janeiro de 2007, de http://www. npt.ufpr.br/

Thielen, I. P., Hartmann, R. C., \& Soares, D. P. (2008). Percepção de risco e excesso de velocidade. Cadernos de Saúde Pública, 24(1),131-139. 